\title{
Clinicopathological evaluation of abnormal uterine bleeding in perimenopausal women
}

\author{
Lithingo Lotha ${ }^{1}$, Asha Borah ${ }^{2}$ \\ ${ }^{1}$ Department of Obstetrics and Gynaecology, ${ }^{2}$ Department of Pathology, Assam Medical College and Hospital,
} Dibrugarh, Assam, India

Received: 08 July 2016

Accepted: 05 August 2016

*Correspondence:

Dr. Lithingo Lotha,

E-mail: dr_1_lotha@yahoo.com

Copyright: ( ) the author(s), publisher and licensee Medip Academy. This is an open-access article distributed under the terms of the Creative Commons Attribution Non-Commercial License, which permits unrestricted non-commercial use, distribution, and reproduction in any medium, provided the original work is properly cited.

\section{ABSTRACT}

Background: Abnormal uterine bleeding is considered as one of the most common and challenging problem presenting to the gynecologist. It is responsible for as many as one third of all outpatient gynaecological visits. This study was carried out in the department of Obstetrics and Gynaecology, Assam Medical College and Hospital, Dibrugarh to evaluate clinically gynaecological causes and the endometrial pattern of abnormal uterine bleeding in perimenopausal women.

Methods: This is a retrospective study of 148 perimenopausal women with complain of abnormal uterine bleeding in the age group ranging from 40-50 years for a period of one year from 01 November 2014 to 30 November 2015. The age, parity, menstrual complaints were noted and clinical diagnosis with ultrasound report and histopathological reports (of endometrial tissue) were analyzed. Finally the histopathological report of the hysterectomy specimen was correlated.

Results: Menorrhagia was the commonest complaint. AUB was seen more in multiparous women (64.8\%). Fibroid uterus was the commonest cause which is $52.7 \%$ followed by DUB $41.2 \%$, adenomyosis $4.7 \%$, and uterine malignancy $1.3 \%$.

Conclusions: Clinicopathological evaluation of AUB showed that fibroid uterus followed by DUB is the most common cause in perimenopausal women. Occurrences of endometrial hyperplasia increases in perimenopause which is of great value as it is a forerunner of carcinoma.

Keywords: Abnormal uterine bleeding, Histopathology, Perimenopause

\section{INTRODUCTION}

Abnormal uterine bleeding accounts for more than $70 \%$ of all gynaecological consultations in the perimenopausal and postmenopausal years. ${ }^{1}$ It is estimated that $9-30 \%$ women suffer from menorrhagia. The prevalence increases with age, peaking just prior to menopause. Thus, making perimenopausal women vulnerable. ${ }^{2}$

WHO defines perimenopause as the time period 2-8 years preceding menopause and 1 year after the final menopause. However a better practical definition is the phase preceding the menopause generally occurring around 40-50 years (average 45.52- 47.5 years). Perimenopausal period usually lasts for around 4 years. Follicular development at this time has been demonstrated to be erratic with increased percentage of anovulatory cycles and variability in oestrogen levels. Any deviation in terms of cycle, duration of bleeding, amount of blood loss or combination of all is called abnormal uterine bleeding. When it is not associated with any organic cause it is termed dysfunctional uterine bleeding. Menorrhagia is defined as excessive uterine bleeding that is more than 7 days. Polymenorrhoea, metrorrhagia, intermenstrual bleeding were other common complaints at perimenopause. Histological 
variations of the endometrium can detect the cause of the disorders taking into account the age and phase of a menstrual cycle. Endometrial hyperplasia is important clinically because it may cause abnormal bleeding, be associated with oestrogen producing ovarian tumors, result from harmone replacement therapy and precede or occur simultaneously with endometrial carcinoma.

\section{METHODS}

This is a retrospective study of 148 perimenopausal women with complaints of abnormal uterine bleeding in the age group ranging from 40-50 years. Pregnant women with bleeding during pregnancy and patients receiving cyclical harmones were excluded. Based on the history and sonographic picture a clinical diagnosis was made. Finally a tissue specimen of the endometrium was obtained by dilatation and curettage procedure. The tissue samples were stained by hamatoxylin and eosin stain.

\section{RESULTS}

One hundred and forty eight cases attending the Gynaecology OPD fulfilling the inclusion and exclusion criteria were selected and studied over a period of one year. Most of the cases of AUB were multiparous (64.9\%) followed by grandmultiparous (18.2\%), primiparous $(10.8 \%)$ and nulliparous $(6.1 \%)$ (Table 1$)$.

Table 1: Relationship of perimenopausal women presenting with AUB and parity.

\begin{tabular}{|lll|}
\hline Parity & Number & Percentage (\%) \\
\hline Nulliparous & 9 & 6.1 \\
\hline Primiparous & 16 & 10.8 \\
\hline Multiparous & 96 & 64.9 \\
\hline Grand multiparous $(\geq 4)$ & 27 & 18.2 \\
\hline Total & $\mathbf{1 4 8}$ & $\mathbf{1 0 0}$ \\
\hline
\end{tabular}

Table 2: Overview of causes of AUB in perimenopausal women.

\begin{tabular}{|lll|}
\hline Causes of AUB & Number & Percentage (\%) \\
\hline Non organic causes & 61 & 41.3 \\
\hline Organic causes & 87 & 58.7 \\
\hline Total & $\mathbf{1 4 8}$ & $\mathbf{1 0 0}$ \\
\hline
\end{tabular}

Table 3: Distribution of causes of AUB.

\begin{tabular}{|lll|}
\hline Clinical causes of AUB & Number & Percentage (\%) \\
\hline Leiomyoma & 78 & 52.7 \\
\hline DUB & 61 & 41.3 \\
\hline adenomyosis & 7 & 4.7 \\
\hline Endometrial carcinoma & 2 & 1.3 \\
\hline Total & $\mathbf{1 4 8}$ & $\mathbf{1 0 0}$ \\
\hline
\end{tabular}

Maximum cases presented with organic causes $(58.7 \%)$ followed by non-organic causes $(41.3 \%)$ (Table 2). Out of the various causes of abnormal uterine bleeding, women in perimenopause most commonly were clinically diagnosed to have leiomyoma $(52.7 \%)$ followed by DUB $(41.3 \%)$, adenomyosis $(4.7 \%)$ and endometrial carcinoma (1.3\%) (Table 3).

\section{Table 4: Pattern of distribution of histopathology of endometrium in AUB.}

\begin{tabular}{|lll|}
\hline Type of endometrium & Number & $\begin{array}{l}\text { Percentage } \\
(\%)\end{array}$ \\
\hline Proliferative endometrium & 61 & 41.4 \\
\hline Secretory endometrium & 8 & 5.4 \\
\hline Endometrial hyperplasia & 72 & 48.6 \\
\hline Atrophic endometrium & 3 & 2.0 \\
\hline Adenocarcinoma & 2 & 1.3 \\
\hline $\begin{array}{l}\text { Chronic inflammatory } \\
\text { endometrium }\end{array}$ & 2 & 1.3 \\
\hline Total & $\mathbf{1 4 8}$ & $\mathbf{1 0 0}$ \\
\hline
\end{tabular}

Most common bleeding disturbance was menorrhagia (49\%) followed by polymenorrhagia $(24 \%)$, metrorrhagia (11\%), menometrorrhagia (8\%), polymenorrhoea $(6 \%)$ and oligomenorrhoea $(2 \%)$. In the present study the overall occurrence of endometrial hyperplasia was $48.6 \%$. Proliferative endometrium was the second most common pattern seen in $41.4 \%$ followed by secretory endometrium (5.4\%), atrophic endometrium (2\%), adenocarcinoma $(1.3 \%)$ and chronic inflammatory endometrium (2\%) (Table 4).

\section{DISCUSSION}

AUB is a common gynaecological disorder in perimenopausal women. Menstrual cycle often becomes irregular due to decreased number of ovarian follicles and increased resistance to gonadotrophic stimulation resulting in low levels of oestrogen which cannot keep the normal endometrium growing. ${ }^{3}$ As endometrium is dynamic and hormomally sensitive and responsive tissue, it constantly undergoes changes throughout the reproductive life; therefore is vulnerable for pathological lesions.

In the present study the highest number of cases were seen in multiparous women $(64.9 \%)$ which is in concordance with the studies done by Mehrotra VG et al, Pilli GS et al, Zarawar et al, Archana B et al. ${ }^{4-7}$ Occurrence of abnormal uterine bleeding increased with parity and a fewer cases were seen in grand multiparous group as their relative frequency has decreased in recent times. Most common organic cause of AUB was fibroid uterus $(58.7 \%)$ followed by DUB $(41.3 \%)$ which tallies with Archana B et al, Rashida $\mathrm{H}$ et al, Ghani NA et al. ${ }^{8,9}$ Menorrhagia was the most common bleeding disorder (49\%) which was also found in studies by Debdas AK et al, Mahmood MF et al, Sarawat A et al, Arti R et al. ${ }^{10-13}$ The most common histological picture seen in the perimenopausal women was that of endometrial hyperplasia $(48.6 \%)$ which tallies with Smita $\mathrm{S}$ et al, 
Saraswathi D et al, Zeeba S et al. ${ }^{14-16}$ The spectrum of proliferation of the endometrium includes disordered growth at one end with carcinomas at the other and intervening stages of hyperplasia. Thus, lies the importance of their early detection. The occurrence peaks around the fifth decade due to persistent anovulation and other factors which predispose to high oestrogen exposure at perimenopause. Histopathological evaluation of endometrial curetting yielded various patterns ranging from physiological to pathological lesions of endometrium. The identification of endometrial hyperplasia is very important. The bleeding in the proliferative phase may be due to anovulatory cycles and the bleeding in secretory phase may be due to ovulatory dysfunctional uterine bleeding which is characterized by increase in the amount of flow. Thus this result supports the importance of diagnostic $\mathrm{D}$ and $\mathrm{C}$ in perimenopausal patients as it helps in identifying the organic causes of AUB in this age group, and to introduce a rational basis for their management.

\section{CONCLUSION}

Abnormal uterine bleeding predominantly affects women of perimenopausal age group which is alarming and needs thorough evaluation as it could be the only clinical manifestation of endometrial carcinoma. In the present study fibroid and DUB were the common causes of abnormal uterine bleeding. Menorrhagia was the commonest presentation. All these patients underwent dilatation and curettage (D and C) or hysterectomy depending on the clinical diagnosis. Histopathology revealed endometrial hyperplasia and proliferative endometrium in most of the cases. Dilatation and curettage is a cheap, cost effective and widely available method for sampling the endometrium and as such can be employed wherever indicated to obtain a tissue diagnosis. Though hysterectomy remained the commonest method of intervention, it is the responsibilities of health care professionals to encourage implementation of alternative procedures to ensure that women receive maximum benefits with least morbidity.

\section{ACKNOWLEDGEMENTS}

Authors would like to thank Department of Obstetrics and Gynaecology and Department of Pathology, Assam Medical College and Hospital, Dibrugarh, Assam, India.

Funding: No funding sources Conflict of interest: None declared

Ethical approval: Not required

\section{REFERENCES}

1. Spencer CP. Whitehead MI. Endometrial assessment revisited. B J obset gynecol. 1999;106:623-32.

2. Chabra S, Jaswal M, Nangia V. Uterine size, endometrium, fertility in women with dysfunctional uterine bleeding. $\mathrm{J}$ obstet gynaecol India. 1992;42:623-32.

3. Davey DA. Dysfunctional uterine bleeding. In Whitfield CR editor; Dewhursts Textbook of Obstetrics and Gynaecology for postgraduates. Glasgow, Blackwell Science. 1997:590-608.

4. Mehrotra VG, Mukherjee K, Pandey M, Samanth V. Abnormal uterine bleeding (a review of 150 cases). J of Obstet Gynecol India. 1972;22:684-9.

5. Pilli GS, Seth SB. Dysfunctional uterine bleeding-a study of 100 cases. J Obstet Gynecol of India. 2002;52(3):87-9.

6. Zarawar MP, Bolde S. Histopathological study of endometrium in dysfunctional uterine bleeding. Solapur Med J. 2005;1(4).

7. Archana B, Michelle F. Evaluation and histopahological correlation of abnormal uterine bleeding in perimenopausal women. J Bombay Hosp. 2010;52:69-72.

8. Hafiz R, Ali M, Ahmad M. Fibroid as a causative factor in menorrhagia and its management. Pakistan $\mathrm{J}$ Med Res. 2003;42;3.

9. Ghani NA, Abdulrajak AA, Abdullah EM. Abnormal uterine bleeding: a histopathological study. World Research Journal of Clinical Pathology. 2012;1(1): 6-8.

10. Debdas AK, Bahol A. Histological profile of diagnostic endometrial curettage and its significance. J of the Indian Med Assoc. 1984;82:309-12.

11. Mahmood MF. Irregular uterine bleeding over the age of 40 years. Ind J Obstet Gynecol. 1988;2(1):2-6.

12. Sarawat A, Roohi M. Histological diagnosis by conventional dilatation and curettage. Professional Med J. 2011;18(4):587-91.

13. Arti R, Nayan A. Abnormal uterine bleeding-a clinicopathological study of 160 cases. Asian J Med Res. 2013;2(1):15-8.

14. Smita S. Validation of endometrial curettage in abnormal uterine bleeding in a teaching institute of Central India: a prospective study. Int J Med Res Health Sci. 2013;2(3):491-5.

15. Saraswati D, Thanka J. Study of endometrial pathology in abnormal uterine bleeding. J Obstet Gynecol of India. 2011;61(4):426-30.

16. Zeeba S. Atypical uterine bleeding-histopathological audit of endometrium. A study of 638 cases. Al amen j Med Sci. 2013;6(1):21-8.

Cite this article as: Lotha L, Borah A.

Clinicopathological evaluation of abnormal uterine bleeding in perimenopausal women. Int J Reprod Contracept Obstet Gynecol 2016;5:3072-4. 